\title{
A Missing Link in Radial lon Transport: Ion Transporters in the Endodermis
}

\author{
Zhulatai Bao ${ }^{1}$, Juan $\mathrm{Bai}^{2}$, Hongchang Cui ${ }^{1,3 *}$ and Chunmei Gong ${ }^{2 *}$ \\ ${ }^{1}$ College of Life Sciences, Northwest A\&F University, Yangling, China, ${ }^{2}$ College of Horticulture, Northwest A\&F University, \\ Yangling, China, ${ }^{3}$ Department of Biological Science, Florida State University, Tallahassee, FL, United States
}

\section{OPEN ACCESS}

Edited by: Joshua Blakeslee, The Ohio State University, United States

Reviewed by:

Jose M. Colmenero-Flores, Spanish National Research Council (CSIC), Spain

Daniel Pergament Persson, University of Copenhagen, Denmark

${ }^{*}$ Correspondence: Hongchang $\mathrm{Cu}$ hcui@bio.fsu.edu

Chunmei Gong gcm228@nwafu.edu.cn; gcm228@nwsuaf.edu.cn

Specialty section:

This article was submitted to Plant Traffic and Transport,

a section of the journal

Frontiers in Plant Science

Received: 13 November 2018

Accepted: 14 May 2019

Published: 04 June 2019

Citation:

Bao Z, Bai J, Cui H and Gong C (2019) A Missing Link in Radial lon Transport: Ion Transporters in the Endodermis.

Front. Plant Sci. 10:713. doi: 10.3389/fpls.2019.00713
In higher plants, roots have important functions, such as the acquisition of water and ions, as well as transportation into the aerial parts of the plant via the xylem vessels. Radial ion transport in the root is strongly regulated in the endodermis, which is characterized by the presence of the Casparian strip (CS) and suberin lamellae. Although tremendous progress has been made with regard to the ion transporters and endodermal cells, little is known about the relationship between the ion transporters in the endodermis and ion homeostasis in aboveground tissues. This review summarizes the current knowledge about the location of the ion transporters (or channels) in the endodermis. We mainly discuss the effects of mutants related to the CS and/or suberin formation on the role of endodermal ion transporters in ion homeostasis. We also wish to emphasize the critical role of endodermal ion transporters in the regulation of radial ion transport in the root.

Keywords: root, endodermis, Casparian strip, suberin, ion transporter

\section{INTRODUCTION}

The root system plays an indispensable role during the uptake of mineral ions. In the roots, various cell layers are organized in concentric rings around the vascular tissues, which are, from the outside to the inside, the epidermis, exodermis (if exists), cortex, and endodermis (Steudle and Peterson, 1998). To reach the xylem, however, ions traveling in the apoplast have to pass through the endodermis via transporter proteins, due to the presence of the Casparian strip (CS) (Pauluzzi et al., 2012; Andersen et al., 2015). Therefore, ion transporters located in the plasma membrane of the endodermis are particularly important and deserve more attention.

Substantial progress has been made in the identification of various types of ion transporters in the root, in addition to the understanding of ion absorption and long-distance transport (Shi et al., 2002; Lin et al., 2008; Véry et al., 2014). Many transporter proteins in Arabidopsis thaliana have also been uncovered by membrane proteomic approaches (Alexandersson et al., 2004; Brugiere et al., 2004; Carter et al., 2004). Among the membrane ion transporters, a few are expressed ubiquitously while others are located only in the endodermis. From a functional point of view, ion transporters expressed in the endodermis represent a missing link in our understanding of the rootto-shoot ion transport pathway, which is essential to ion homeostasis in aboveground tissues. The endodermal ion transporters (or channels) discovered in Arabidopsis thaliana, rice (Oryza sativa), barley (Hordeum vulgare), and maize (Zea mays) are summarized in Table $\mathbf{1}$ and Figure $\mathbf{1}$. 


\section{TRANSPORT ROUTES FOR IONS IN THE ROOT}

The movement of water and solutes in the root has been classified into three pathways: the apoplastic pathway, symplastic pathway, and coupled transcellular pathways (Figure 1; Steudle, 2000). The apoplastic pathway provides a route for ions to reach the stele, by diffusing through the cell walls and free spaces between cells (Barberon and Geldner, 2014). The rate of diffusion depends upon the ionic gradient between the external solution and apoplastic free space (Barberon and Geldner, 2014). A strictly apoplastic flow from the soil to the stele can occur only prior to CS differentiation or at the site of CS disruption, for example, at a site of lateral root emergence (Krishnamurthy et al., 2011; Barberon and Geldner, 2014). Apoplastic flow is less controlled and non-selective where molecules diffuse along the concentration gradient or move with the bulk water flow driven by transpiration (Steudle and Peterson, 1998; Steudle, 2000; Enstone et al., 2003; Barberon and Geldner, 2014). After uptake by the epidermal cells, ions can be transported via the symplastic pathway through the connections between the cells provided by plasmodesmata (Andersen et al., 2015). The transport rate through the symplastic pathway depends upon the density and size exclusion limit of plasmodesmata (Stahl and Simon, 2013; Barberon and Geldner, 2014). Additionally, ions can repeatedly cross plasma membranes through transporter proteins, a transport route usually referred to as the coupled transcellular pathway (Robbins et al., 2014). Overall, ion transportation via polarly localized ion transporters in the plasma membrane is more directional compared to the apoplastic pathway (Geldner, 2013).

\section{CS AND SUBERIN MAKE THE ENDODERMIS AN EFFECTIVE BARRIER}

In Arabidopsis, endodermis differentiation can be divided into two stages: the CS formation at the first stage, and "patchy" appearance of suberin lamellae at the second stage that gradually enclose the whole cell in an upward direction along the longitudinal axis (Naseer et al., 2012; Geldner, 2013; Barberon and Geldner, 2014; Andersen et al., 2015; Barberon, 2016). The CS is a belt-like lignin-based structure, which forms in the middle of the anticlinal walls of the endodermal cells (Enstone et al., 2003; Andersen et al., 2015). The CS is tightly adhered to the plasma membrane and spans the apoplastic space between adjacent endodermal cells, thus completely isolating the apoplast of the stele from the apoplast of the outer tissue layers (Naseer et al., 2012; Robbins et al., 2014). Although semi-permissive, the plasma membrane sometimes fails to prevent the entry of undesirable compounds due to passive diffusion (Robbins et al., 2014). Deposited as a secondary cell wall between the primary cell wall and plasma membrane, the suberin lamellae can cover the entire surface of the endodermal cells as the root matures (Geldner, 2013). The presence of suberin lamellae potentially blocks the direct uptake of nutrients from the apoplast into the endodermal cells (Geldner, 2013; Robbins et al., 2014).
Ultimately, the efficient and selective sorting of nutrients is accomplished at the endodermis level (Enstone et al., 2003; Alassimone et al., 2012). For example, in rice, exposure to moderate salt stress results in the enhancement of suberization and significant reduction in sodium accumulation in the shoot (Krishnamurthy et al., 2009, 2011). In maize roots, accelerating suberin deposition in the endodermis has been shown to restrict the radial apoplastic movement of cadmium $(\mathrm{Cd})$ and $\mathrm{Cd}$ loading in the xylem (Lux et al., 2011).

Together with previous studies, Barberon et al. (2016) clearly defined the function of the CS from that of the suberin lamellae: the CS blocks the passage between the endodermal cells, while suberin lamellae suppresses the uptake into the cytoplasm of the endodermis (Naseer et al., 2012; Hosmani et al., 2013; Pfister et al., 2014; Kamiya et al., 2015; Barberon et al., 2016). In Arabidopsis, ion accumulation in the leaves of CS defective mutants, such as myb36, esb1, casp1casp3, and sgn3, is significantly altered under normal growth conditions (Baxter et al., 2009; Roppolo et al., 2011; Hosmani et al., 2013; Pfister et al., 2014; Kamiya et al., 2015; Barberon et al., 2016). Among them, myb36, esb1, and casp1casp3 show compensatory deposition of suberin (Pfister et al., 2014). The potassium (K) content in a sgn3 leaf is decreased, which is accompanied by an increase in magnesium (Mg) (Pfister et al., 2014). However, the ion concentrations in myb36, esb1, and casp1casp3 leaves have been further disrupted due to suberin enhancement, which suggests that suberin deposition impacts the ion transport from the roots to shoots. As a secondary cell wall modification, suberin restricts the access of nutrients to the plasma membrane of the endodermis (Geldner, 2013). Hence, it can also be suggested that suberin hinders the access of ions to endodermal ion transporters. Concerning leaf ion homeostasis, striking similarities have been reported between $m y b 36$, esb1, and casplcasp3, all of which show a reduction in the iron $(\mathrm{Fe})$ and manganese $(\mathrm{Mn})$ contents (Hosmani et al., 2013; Kamiya et al., 2015). Notably, the Fe transporter, AtYSL2, is located in the endodermis (Figure 1; Schaaf et al., 2005). In rice, the natural resistance-associated macrophage protein 5 (OsNramp5) and metal tolerance protein 9 (OsMTP9) are known to be located in the distal and proximal sides of the endodermis, respectively, mediating the direct transport of Mn across the endodermal cells (Figure 1 and Table 1; Sasaki et al., 2012; Ueno et al., 2015; Shao et al., 2017). The spatial distribution and cellular localization of Mn transporters in Arabidopsis are not as well understood as those in rice (Shao et al., 2017). However, it is known that in Arabidopsis, Fe- and Mn-deficiency decreases suberization, compared to control plants. A dramatic reduction in the extent of suberization has been observed in mutants of the iron-regulated transporter1 (irt1) and natural-resistance-associated macrophage proteins1 (nramp1), consistent with the effects of Fe and $\mathrm{Mn}$ deficiency on suberization (Barberon et al., 2016). One possible explanation for the alteration in the $\mathrm{Fe}$ and $\mathrm{Mn}$ contents in $m y b 36$, esb1, and casplcasp 3 is that the enhanced suberization in these mutants impedes the transporter protein mediated Fe/Mn transport into the endodermis. Moreover, suberization of both the endodermis and exodermis in rice is delayed under $\mathrm{NH}_{4}^{+}$-deficient conditions (Ranathunge et al., 2016). In contrast, 
TABLE 1 | Localization of ion transporter (or channel) genes on the root cell.

\begin{tabular}{|c|c|c|c|c|c|c|c|}
\hline Gene & Substrate & ep & ex & co & en & Polarity & References \\
\hline AtNRT1.1 & Nitrate & $\sqrt{ }$ & & $\sqrt{ }$ & $\sqrt{ }$ & & Huang et al., 1996 \\
\hline AtNRT2.1 & Nitrate & $\sqrt{ }$ & & $\sqrt{ }$ & $\sqrt{ }$ & & Nazoa et al., 2003 \\
\hline AMT1;2 & Ammonium & & & & $\sqrt{ }$ & & Neuhäuser et al., 2007 \\
\hline AtPT1 & Phosphate & $\sqrt{ }$ & & & $\sqrt{ }$ & & Karthikeyan et al., 2002 \\
\hline$A K T 1$ & Potasium & $\sqrt{ }$ & & $\sqrt{ }$ & $\sqrt{ }$ & & Lagarde et al., 1996 \\
\hline AtKC1 & Potasium & $\sqrt{ }$ & & $\sqrt{ }$ & $\sqrt{ }$ & & Reintanz et al., 2002 \\
\hline AtYSL2 & Iron/Zinc & & & & $\sqrt{ }$ & & Schaaf et al., 2005 \\
\hline AtIRT3 & Iron/Zinc & & & & $\sqrt{ }$ & & Lin et al., 2009 \\
\hline NIP5;1 & Boron & $\sqrt{ }$ & & $\sqrt{ }$ & $\sqrt{ }$ & Distal & Takano et al., 2008 \\
\hline$B O R 1$ & Boron & & & & $\sqrt{ }$ & Proximal & Takano et al., 2008 \\
\hline Nramp1 & Manganese & $\sqrt{ }$ & & $\sqrt{ }$ & $\sqrt{ }$ & & Cailliatte et al., 2010 \\
\hline HVYSL2 & Iron & & & & $\sqrt{ }$ & & Araki et al., 2011 \\
\hline HVST1 & Sulfate & $\sqrt{ }$ & & $\sqrt{ }$ & $\sqrt{ }$ & & Rae and Smith, 2002 \\
\hline HvLsi2 & Silicon & & & & $\sqrt{ }$ & & Mitani et al., 2009 \\
\hline ZmLsi2 & Silicon & & & & $\sqrt{ }$ & & Mitani et al., 2009 \\
\hline OsPT8 & Phosphate & $\sqrt{ }$ & & $\sqrt{ }$ & $\sqrt{ }$ & & Jia et al., 2011 \\
\hline OsAKT1 & Potasium & $\sqrt{ }$ & $\sqrt{ }$ & $\sqrt{ }$ & $\sqrt{ }$ & & Li et al., 2014 \\
\hline OsYLS15 & Iron & $\sqrt{ }$ & $\sqrt{ }$ & $\sqrt{ }$ & $\sqrt{ }$ & & Lee et al., 2009 \\
\hline OsLsi1 & Silicon & & $\sqrt{ }$ & & $\sqrt{ }$ & Distal & Ma et al., 2006 \\
\hline OsLsi2 & Silicon & & $\sqrt{ }$ & & $\sqrt{ }$ & Proximal & Ma and Yamaji, 2015 \\
\hline OsNramp5 & Manganese/Cadmium & & $\sqrt{ }$ & & $\sqrt{ }$ & Distal & Sasaki et al., 2012 \\
\hline OsMTPg & Manganese & & $\sqrt{ }$ & & $\sqrt{ }$ & Proximal & Ueno et al., 2015 \\
\hline OsNIP3;1 & Boron & & $\sqrt{ }$ & & $\sqrt{ }$ & Distal & Takano et al., 2008 \\
\hline OsBOR1 & Boron & & $\sqrt{ }$ & & $\sqrt{ }$ & Proximal & Nakagawa et al., 2007 \\
\hline
\end{tabular}

*Slash represents the species lacking exodermal cell. ep, Epidermis; ex, exodermis; co, cortex; en, endodermis.

suberin is deposited early and close to the apex of the roots under high $\mathrm{NH}_{4}^{+}$conditions (Ranathunge et al., 2016). The authors also suggest that, compared to a fully suberized cell layer, patchy suberin may provide the transporters in the plasma membrane a higher access to $\mathrm{NH}_{4}^{+}$(Ranathunge et al., 2016). In a recent study, it was shown that esb1 and myb36 had a lower amount of ${ }^{15} \mathrm{NH}_{4}^{+}$in the shoots (Duan et al., 2018). Therefore, a detailed analysis about the impacts of suberin deposition on endodermal ion transporters is required.

Magnesium is another element that is affected in all the above-described mutants. Magnesium transport 1 (MGT1) and MGT6 are two plasma membrane transporters involved in the uptake of $\mathrm{Mg}$ in Arabidopsis roots (Li et al., 2001; Mao et al., 2014). Although both of them are expressed in the vascular tissues, MGT6 is significantly up-regulated when seedlings are transferred from Mg-sufficient to -deficient conditions (Mao et al., 2014). Interestingly, the expression domain of MGT6 is even extended to the cortex and epidermis (Mao et al., 2014).
Additionally, Ogura et al. (2018) demonstrated that Mg uptake under Mg-sufficient conditions is particularly sensitive to the inhibitory effects of gadolinium (Gd) and Fe, but not of $\mathrm{K}$. Nevertheless, the information available about the effects of $\mathrm{Mg}$ deficiency on suberin deposition is still lacking.

The research described above lends strong support to the notion that the endodermis is a checkpoint for ion accumulation in the shoots.

\section{ION TRANSPORTERS IN THE ENDODERMIS}

\section{Non-polarly Localized Transporters}

As an important component of the endodermal barrier, ion transporters determine which ion can enter the stele and, thus, act as a gateway controlling the ins and outs of ions. Figure 1 illustrates the ion transporters (or channels) with an 


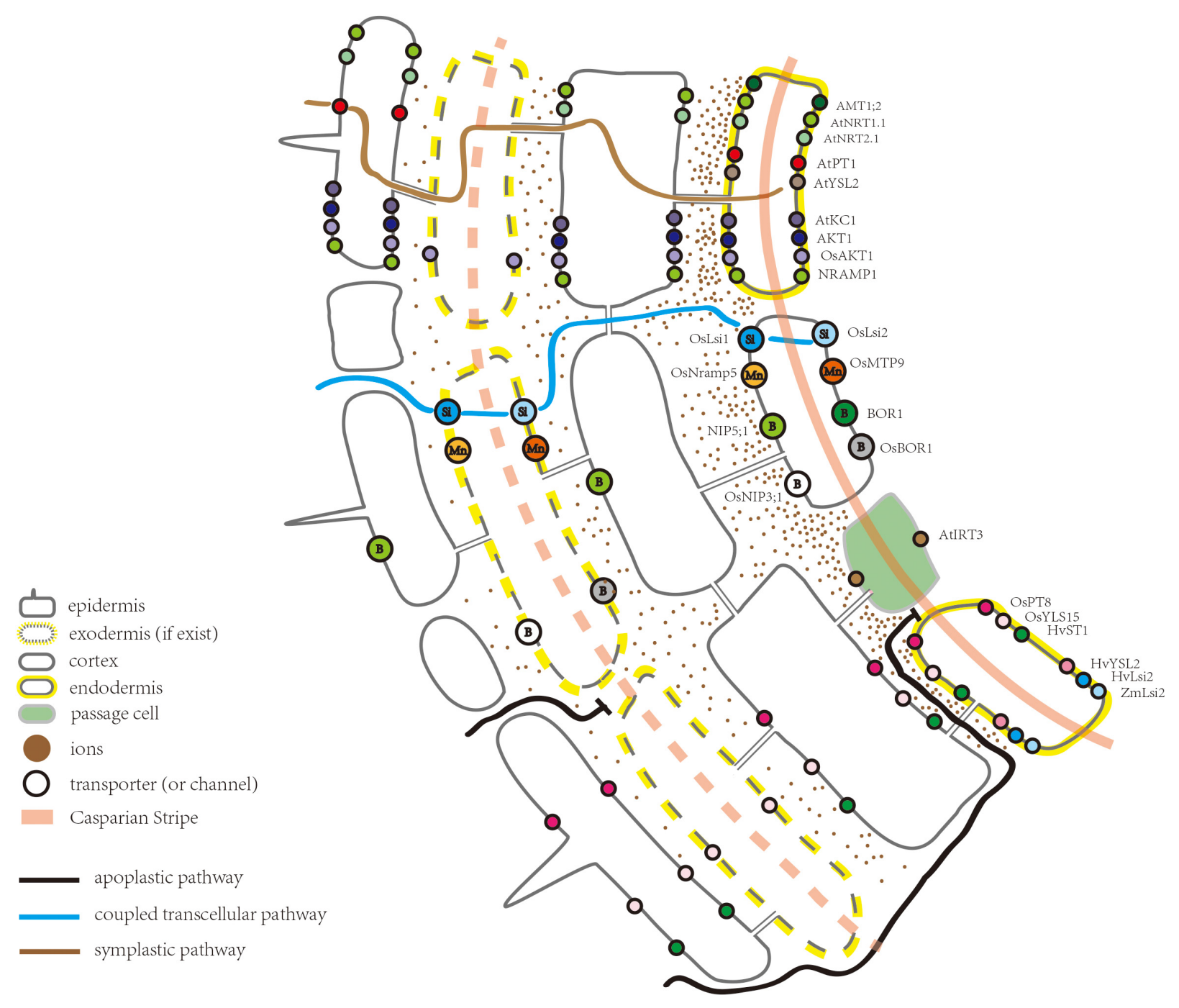

FIGURE 1 | Schematic of part of a root highlighting the ion transporters (or channels) located in the endodermis.

endodermal localization, including those for nitrate, ammonium, phosphate, potassium, sulfate, iron, and zinc. Except for iron transporter AtIRT3, however, these transporters (or channels) are not exclusively expressed in the endodermis (Lin et al., 2009). Through these transporters (or channels), ions can enter the symplastic route for radial transportation toward the root stele and are eventually loaded into the xylem. In Arabidopsis roots, the nitrate transporter2.1 (AtNRT2.1), ammonium transporter1;2 (AMT1;2), chlorate resistant 1 (CHL1/AtNRT1.1), and inwardrectifier $\mathrm{K}^{+}$channel (AKT1) are all highly expressed in the mature region of the root. However, the degree of suberization in the mature region remains unclear. Huang et al. (1996) suggested that CHL1 and AKT1 have similar but unidentical patterns of gene expression. In root cells close to the root tip, CHL1 is mainly expressed in the epidermal cells, whereas in the older part, CHL1 is expressed in the cortex and endodermis, and its expression domain becomes restricted to the endodermis (Huang et al., 1996). Thus, it seems the cells that are important for ion uptake, tend to be more internally localized as the roots become more mature (Huang et al., 1996). This trend is consistent with and probably due to a more conductive xylem tissue in the mature zone and a higher water demand, driven by the transpiration stream, where water demand is essentially driven by cell elongation (Hachez et al., 2006). In any case, there is no doubt that transporters expressed in the endodermis play an important role in controlling the uptake of ions from the apoplast of the outer cell layers into the endodermal cytoplasm and further entry into the stele. In line with this notion, some studies have suggested that the endodermis serves as a filter, damping the ion movement at the site of the CS and, as a result, ion concentrations are likely higher near the endodermis (Enstone et al., 2003). In support of this view, in Arabidopsis roots, ammonium is confined to the apoplast closest to the endodermis, and AMT1;2 has a much higher Km than that of the transporters located in the rhizodermis, such as AMT1;1 and AMT1;3 (Yuan et al., 2007). This observation has lead (Yuan 
et al., 2007) to conclude that there is a spatial distribution of AMT1 transporters - those possessing higher substrate affinities are located in the outer root cells, whereas those with a lower affinity are located at the end of the apoplastic transport pathway. Under high ammonium concentrations, AMT1;2 in the endodermis favors ammonium partitioning to the shoot (Duan et al., 2018). In addition, the expression of another ammonium transporter, AMT2; 1 , becomes more confined to the endodermal and pericycle cells when only ammonium is present (Giehl et al., 2017). As a result, the co-expression of AMT2;1 with AMT1;2 in the amt1;1 amt1;2 amt1;3 amt2;1 quadruple mutant, significantly enhances the ${ }^{15} \mathrm{~N}$ translocation to the shoot (Giehl et al., 2017). These studies indicate that the endodermal localization of ammonium transporters is critical for ammonium partitioning to the shoot.

\section{Polarly Localized Transporters}

The asymmetric distribution of the influx and efflux proteins in endodermal cells is believed to be a key factor driving the directional solute movement toward the stele and preventing backflow when transpiration is low (Sakurai et al., 2008; Robbins et al., 2014). However, only a few examples of the polar localization of ion transporters (or channels) have been reported (Figure 1). For example, Ma and Yamaji (2015) demonstrated that polar localization of the silicon influx channel, low silicon rice 1, and silicon exporter, silicon rice2, are essential for silicon transport in rice roots (Ma et al., 2006, 2007; Ma and Yamaji, 2015). Both of them are expressed in the exodermis and endodermis, providing the coupled transcellular pathway directing Si toward the stele. Like the Si transporter, the boric acid/borate exporter (OsBOR1) in rice spans the exodermal CS, as well as the endodermis. Together, these OsBOR1 proteins provide a transcellular efflux pathway for the directional movement of boron (B) (Nakagawa et al., 2007). In Arabidopsis, the boric acid channel, NIP5;1, is required for B uptake under $\mathrm{B}$ deficiency conditions, whilst the boric acid exporter, BOR1, excludes borate from cells close to the xylem (Figure 1; Takano et al., 2005, 2008). Wang et al. (2017) demonstrated that the polar localization of NIP5;1 is maintained by clathrin-mediated endocytosis (Nakamura and Grebe, 2018). However, high levels of $\mathrm{B}$ are toxic to plants. To avoid toxicity, BOR1 is transported to the vacuole wherein it is degraded (Takano et al., 2005, 2010; Nakamura and Grebe, 2018). Another mechanism to reduce $B O R 1$ expression under high $B$ levels is through the transcriptional repression of BOR1, mediated by BOR1 $5^{\prime}$-UTR (Aibara et al., 2018). In rice, OsNramp5 is located at the distal side of the exodermis and endodermis and is responsible for the transportation of Cd (not essential for plant growth), Mn, and Fe (Figure 1; Sasaki et al., 2012). However, the Arabidopsis Nramp1 is located in all root cell layers (Figure 1; Cailliatte et al., 2010). When knocked out, Nramp1 and OsNramp5 mutants also have different phenotypes (Sasaki et al., 2012). In contrast to the OsNramp5 knockout line, the decreased Mn concentration in the shoot of Nramp1 knockout lines can be rescued by a high Mn concentration (Sasaki et al., 2012). This result also suggests that the mediated transport of $\mathrm{Mn}$ is indispensable for the normal growth and development of rice
(Sasaki et al., 2012). The uptake systems for Si, B, and Mn in rice roots have been summarized by Sasaki et al. (2016) and Che et al. (2018).

The contribution of endodermal ion transporters to the ion accumulation in aboveground tissues remains unclear. To answer this question, the tissue specific knockdown of certain ion transporters in the endodermis is required. To our knowledge, only a few studies have demonstrated that $\mathrm{Cd}$ accumulation in rice is strongly decreased when the function of OsNramp5 is defective (Clemens et al., 2012; Sasaki et al., 2012). Sasaki et al. (2012) also demonstrated that the knockout of OsNramp5 results in almost a complete loss of the ability to uptake Cd. Research on Noccaea caerulescens, a $\mathrm{Zn} / \mathrm{Cd}$ hyperaccumulator, revealed that the endodermalexpressed NcNramp1 gene plays a key role in Cd translocation into the stele (Milner et al., 2014).

\section{CONCLUSION AND FUTURE PERSPECTIVES}

The importance of ion transporters in plant growth and development is beyond the question. Their positioning in the endodermis makes them a crucial player in the regulation of ion transport from the roots to shoots. To compare ion transportation across endodermal cells with other cell layers, the ion flux of different cell layers needs to be measured. However, it is not yet possible to directly measure the ion flux of the inner cell layers of the root. This problem could be resolved in the near future, for example, by the non-invasive microelectrode ion flux estimation (MIFE) technique, which has been used to measure the net fluxes of different ions within the root surface. Another issue yet to be addressed is the contribution of endodermal ion transporters to radial ion transport from the roots to shoots. Many ion transporters, such as CHL1, AMT1.1, and AKT1, can serve as sensors of nitrate, ammonium, and potassium, respectively (Ho et al., 2009; Ho and Tsay, 2010). Accordingly, it would be interesting to study whether endodermal ion transporters play such a role, thus making the endodermis a signaling hub. According to Dinneny (2014), the endodermis acts as a signaling center where multiple hormone signals, such as auxin, gibberellic acid, abscisic acid, and strigolactones, are integrated. Data from Li S. et al. (2016) indicate that the ion transporter Nramp1 is co-expressed with lincRNAs. Considering that lincRNAs play important roles during development and in response to stress, they are deserving further research.

As the gene expression atlas at a single cell resolution has become available, cell type specific ion transporters have been identified (Gifford et al., 2008; Geng et al., 2013; Li B. et al., 2016; Ryu et al., 2019). For instance, through the reanalysis of the published database of Evrard et al. (2012), Evrard (2013) and Li B. et al. (2016) identified chloride transporters localized in the stele. Similarly, ion transporters preferentially expressed in the endodermis have also been reported, such as AT4G02090 and AT5G14880, which encode the multidrug resistance protein $\mathrm{ABC}$ transporter family protein and potassium transporter family protein, respectively (Geng et al., 2013; Ryu et al., 2019). 
The formation of the CS and suberin lamellae is closely correlated with the leaf ionome in the esb1, casp1casp3, myb36, and sgn3 mutants (Baxter et al., 2009; Roppolo et al., 2011; Hosmani et al., 2013; Pfister et al., 2014; Kamiya et al., 2015; Barberon et al., 2016). More importantly, the plasticity of suberization in response to nutritional stress has already been highlighted (Barberon et al., 2016). Nevertheless, a number of questions still remain concerning the function of ion transporters in the context of the endodermis. If the degree of suberization changes in the endodermis, will the expression of ion transporters be affected? For those located within the endodermal cell, will their location change? Cell type level investigation using the fluorescence-activated cell sorting (FACS) technique combined with a time series of transcriptomic analyses, as described recently in Walker et al. (2017), may aid in answering these questions.

\section{REFERENCES}

Aibara, I., Hirai, T., Kasai, K., Takano, J., Onouchi, H., Naito, S., et al. (2018). Boron-dependent translational suppression of the borate exporter BOR1 contributes to the avoidance of boron toxicity. Plant Physiol. 177, 759-774. doi: 10.1104/pp.18.00119

Alassimone, J., Roppolo, D., Geldner, N., and Vermeer, J. E. (2012). The endodermis-development and differentiation of the plant's inner skin. Protoplasma 249, 433-443. doi: 10.1007/s00709-011-0302-5

Alexandersson, E., Saalbach, G., Larsson, C., and Kjellbom, K. (2004). Arabidopsis plasma membrane proteomics identifies components of transport, signal transduction and membrane trafficking. Plant Cell Physiol. 45, 1543-1556. doi: $10.1093 / \mathrm{pcp} / \mathrm{pch} 209$

Andersen, T. G., Barberon, M., and Geldner, N. (2015). Suberization - the second life of an endodermal cell. Curr. Opin. Plant. Biol. 28, 9-15. doi: 10.1016/j.pbi. 2015.08.004

Araki, R., Murata, J., and Murata, Y. (2011). A novel barley yellow stripe 1like transporter (HvYSL2) localized to the root endodermis transports metalphytosiderophore complexes. Plant Cell Physiol. 52, 1931-1940. doi: 10.1093/ pcp/pcr126

Barberon, M. (2016). The endodermis as a checkpoint for nutrients. New Phytol. 213, 1604-1610. doi: 10.1111/nph.14140

Barberon, M., and Geldner, N. (2014). Radial transport of nutrients: the plant root as a polarized epithelium. Plant Physiol. 166, 528-537. doi: 10.1104/pp.114. 246124

Barberon, M., Vermeer, J. E., De Bellis, D., Wang, P., Naseer, S., and Andersen, T. G. (2016). Adaptation of root function by nutrient-induced plasticity of endodermal differentiation. Cell 28, 447-459. doi: 10.1016/j.cell.2015.12.021

Baxter, I., Hosmani, P. S., Rus, A., Lahner, B., Borevitz, J. O., Muthukumar, B., et al. (2009). Root suberin forms an extracellular barrier that affects water relations and mineral nutrition in Arabidopsis. PLoS Genet. 5:e1000492. doi: 10.1371/journal.pgen.1000492

Brugiere, S., Kowalski, S., Ferro, M., Seigneurin-Berny, D., Miras, S., Salvi, D., et al. (2004). The hydrophobic proteome of mitochondrial membranes from Arabidopsis cell suspensions. Phytochemistry 65, 1693-1707. doi: 10.1016/j. phytochem.2004.03.028

Cailliatte, R., Schikora, A., Briat, J. F., Mari, S., and Curie, C. (2010). Highaffinity manganese uptake by the metal transporter NRAMP1 is essential for Arabidopsis growth in low manganese conditions. Plant Cell 22, 904-917. doi: 10.1105/tpc.109.073023

Carter, C., Pan, S., Zouhar, J., Avila, E. L., Girke, T., and Raikhel, N. V. (2004). The vegetative vacuole proteome of Arabidopsis thaliana reveals predicted and unexpected proteins. Plant Cell 16, 3285-3303. doi: 10.1105/tpc.104. 027078

Che, J., Yamaji, N., and Ma, J. F. (2018). Efficient and flexible uptake system for mineral elements in plants. New Phytol. 219, 513-517. doi: 10.1111/nph. 15140

\section{AUTHOR CONTRIBUTIONS}

ZB drafted and revised the manuscript. HC, CG, and JB revised the manuscript.

\section{FUNDING}

This work was supported by the National Natural Science Foundation of China (31370599).

\section{ACKNOWLEDGMENTS}

A special thanks to two reviewers who have provided insightful suggestions concerning the improvement to this manuscript.

Clemens, S., Aarts, M. G. M., Thomine, S., and Verbtuggen, V. (2012). Plant science: the key to preventing slow cadmium poisoning. Trends Plant Sci. 18, 92-99. doi: 10.1016/j.tplants.2012.08.003

Dinneny, J. R. (2014). A gateway with a guard: How the endodermis regulates growth through hormone signaling. Plant Sci. 214, 14-19. doi: 10.1016/j. plantsci.2013.09.009

Duan, F., Giehl, R. F. H., Geldner, N., Salt, D. E., and von Wirén, N. (2018). Root zone-specific localization of AMTs determines ammonium transport pathways and nitrogen allocation to shoots. PLoS Biol. 24:e2006024. doi: 10.1371/journal. pbio. 2006024

Enstone, D. E., Peterson, C. A., and Ma, F. (2003). Root endodermis and exodermis: structure, function, and responses to the environment. J. Plant Growth Regul. 21, 335-351. doi: 10.1007/s00344-003-0002-2

Evrard, A. (2013). Cell Type-Specific Transcriptional Responses of Plants to Salinity. University of Adelaide: Adelaide.

Evrard, A., Bargmann, B. R., Birnbaum, K., Tester, M., Baumann, U., and Johnson, A. T. (2012). "Fluorescence-activated cell sorting for analysis of cell typespecific responses to salinity stress in Arabidopsis and rice," in Plant Salt Tolerance, Vol. 913, eds S. Shabala and T. A. Cuin (New York, NY: Humana Press), 265-276. doi: 10.1007/978-1-61779-986-0_18

Geldner, N. (2013). The endodermis. Annu. Rev. Plant Biol. 64, 531-558. doi: 10.1146/annurev-arplant-050312-120050

Geng, Y., Wu, R., Wee, C. W., Xie, F., Wei, X., Chan, P. M., et al. (2013). A spatiotemporal understanding of growth regulation during the salt stress response in Arabidopsis. Plant Cell 25, 2132-2154. doi: 10.1105/tpc.113.112896

Giehl, R. F. H., Laginha, A. M., Duan, F., Rentsch, D., Yuan, L., and von Wirén, N. (2017). A critical role of AMT2;1 in root-to-shoot translocation of ammonium in Arabidopsis. Mol. Plant. 6, 1449-1460. doi: 10.1016/j.molp.2017.10.001

Gifford, M. L., Dean, A., Gutierrez, R. A., Coruzzi, G. M., and Birnbaum, K. D. (2008). Cell-specific nitrogen responses mediate developmental plasticity. PNAS 15, 803-808. doi: 10.1073/pnas.0709559105

Hachez, C., Moshelion, M., Zelazny, E., Cavez, D., and Chaumont, F. (2006). Localization and quantification of plasma membrane aquaporin expression in maize primary root: a clue to understanding their role as cellular plumbers. Plant Mol. Biol. 62, 305-323. doi: 10.1007/s11103-006-9022-1

Ho, C. H., Lin, S. H., Hu, H. C., and Tsay, Y. F. (2009). CHL1 functions as a nitrate sensor in plants. Cell 138, 1184-1194. doi: 10.1016/j.cell.2009.07.004

Ho, C. H., and Tsay, Y. F. (2010). Nitrate, ammonium, and potassium sensing and signaling. Curr. Opin. Plant Biol. 13, 604-610. doi: 10.1016/j.pbi.2010.08.005

Hosmani, P. S., Kamiya, T., Danku, J., Naseer, S., Geldner, N., Guerinot, M. L., et al. (2013). Dirigent domain-containing protein is part of the machinery required for formation of lignin-based Casparian strip in the root. PNAS 110, 14498-14503. doi: 10.1073/pnas.13084

Huang, N. C., Chiang, C. S., Crawford, N. M., and Tsay, Y. F. (1996). CHL1 encodes a component of the low-affinity nitrate uptake system in Arabidopsis and shows cell type-specific expression in roots. Plant Cell 8, 2183-2191. doi: $10.1105 /$ tpc.8.12.2183 
Jia, H., Ren, H., Gu, M., Zhao, J., Sun, S., Zhang, X., et al. (2011). The Phosphate transporter gene OsPht $1 ; 8$ is involved in phosphate homeostasis in rice. Plant Physiol. 156, 1164-1175. doi: 10.1104/pp.111.175240

Kamiya, T., Borghi, M., Wang, P., Danku, J. M., Kalmbach, L., Hosmani, P. S., et al. (2015). The MYB36 transcription factor orchestrates casparian strip formation. PNAS 112, 10533-10538. doi: 10.1073/pnas.1507691112

Karthikeyan, A. S., Varadarajan, D. K., Mukatira, U. T., D’urzo, M. P., Damsz, B., and Raghothama, K. G. (2002). Regulated expression of Arabidopsis phosphate transporters. Plant Physiol. 130, 221-233. doi: 10.1104/pp.020007

Krishnamurthy, P., Ranathunge, K., Franke, R., Prakash, H. S., Schreiber, L., and Mathew, M. K. (2009). The role of root apoplastic transport barriers in salt tolerance of rice (Oryza sativa L.). Planta 230, 119-134. doi: 10.1007/s00425009-0930-6

Krishnamurthy, P., Ranathunge, K., Nayak, S., Schreiber, L., and Mathew, M. K. (2011). Root apoplastic barriers block $\mathrm{Na}+$ transport to shoots in rice (Oryza sativa L.). J. Exp. Bot. 62, 4215-4228. doi: 10.1093/jxb/err135

Lagarde, D., Basset, M., Lepetit, M., Conejero, G., Gaymard, F., Astruc, S., et al. (1996). Tissue-specific expression of Arabidopsis AKT1 gene is consistent with a role in K+ nutrition. Plant J. 9, 195-203. doi: 10.1046/j.1365-313x.1996. 09020195.x

Lee, S., Chiecko, J. C., Kim, S. A., Walker, E. L., Lee, Y., Guerinot, M. L., et al. (2009). Disruption of OsYSL15 leads to iron inefficiency in rice plants. Plant Physiol. 150, 786-800. doi: 10.1104/pp.109.135418

Li, B., Byrt, C., Qiu, J., Baumann, U., Hrmova, M., Evrard, A., et al. (2016). Identification of a stelar-localized transport protein that facilitates root-toshoot transfer of chloride in Arabidopsis. Plant Physiol. 2016, 1014-1029. doi: 10.1104/pp.15.01163

Li, J., Long, Y., Qi, G. N., Li, J., Xu, Z. J., Wu, W. H., et al. (2014). The Os-AKT1 channel is critical for $\mathrm{K}+$ uptake in rice roots and is modulated by the rice CBL1-CIPK23 complex. Plant Cell 26, 3387-3402. doi: 10.1105/tpc.114.123455

Li, L., Tutone, A. F., Drummond, R. S., Gardner, R. C., and Luan, S. (2001). A novel family of magnesium transport genes in Arabidopsis. Plant Cell 13, 2761-2775. doi: 10.1105/tpc.010352

Li, S., Yamada, M., Han, X., Ohler, U., and Benfey, P. N. (2016). High-resolution expression map of the Arabidopsis root reveals alternative splicing and lincRNA regulation. Dev. Cell. 21, 508-522. doi: 10.1016/j.devcel.2016.10.012

Lin, S. H., Kuo, H. F., Canivenc, G., Lin, C. S., Lepetit, M., Hsu, P., et al. (2008). Mutation of the Arabidopsis NRT1.5 Nitrate transporter causes defective root-to-shoot nitrate transport. Plant Cell 20, 2514-2528. doi: 10.1105/tpc.108. 060244

Lin, Y. F., Liang, H. M., Yang, S. Y., Boch, A., Clemens, S., Chen, C. C., et al. (2009). Arabidopsis IRT3 is a zinc-regulated and plasma membrane localized zinc/iron transporter. New Phytol. 182, 392-404. doi: 10.1111/j.1469-8137.2009. 02766.x

Lux, A., Martinka, M., Vaculík, M., and White, P. J. (2011). Root responses to cadmium in the rhizosphere: a review. J. Exp. Bot. 62, 21-37. doi: 10.1093/jxb/ erq281

Ma, J. F., Tamai, K., Yamaji, M., Mitani, N., Konishi, S., Katsuhara, M., et al. (2006). A silicon transporter in rice. Nature 440, 688-691. doi: 10.1038/nature04590

Ma, J. F., and Yamaji, N. (2015). A cooperative system of silicon transport in plants. Trends Plant Sci. 65, 3049-3057. doi: 10.1016/j.tplants.2015.04.007

Ma, J. F., Yamaji, N., Mitani, N., Yamai, K., Konishi, S., Fujiwara, T., et al. (2007). An efflux transporter of silicon in rice. Nature 448, 209-212. doi: 10.1038/ nature 05964

Mao, D., Chen, J., Tian, L., Liu, Z., Yang, L., and Tang, R. (2014). Arabidopsis transporter MGT6 mediates magnesium uptake and is required for growth under magnesium limitation. Plant Cell 26, 2234-2248. doi: 10.1105/tpc.114. 124628

Milner, M. J., Mitani-Ueno, N., Yamaji, N., Yokosho, K., Craft, E., Fei, Z., et al. (2014). Root and shoot transcriptome analysis of two ecotypes of Noccaea caerulescens uncovers the role of NcNramp1 in Cd hyperaccumulation. Plant J. 78, 398-410. doi: 10.1111/tpj.12480

Mitani, N., Chiba, Y., Yamaji, N., and Ma, J. F. (2009). Identification and characterization of maize and barley Lsi2-like silicon efflux transporters reveals a distinct silicon uptake system from that in rice. Plant Cell 21, 2133-2142. doi: 10.1105/tpc.109.067884

Nakagawa, Y., Hanaoka, H., Kobayashi, M., Miyoshi, K., Miwa, K., and Fujiwara, T. (2007). Cell-type specificity of the expression of OsBOR1, a rice efflux boron transporter gene, is regulated in response to boron availability for efficient boron uptake and xylem loading. Plant Cell 19, 2624-2635. doi: 10.1105/tpc. 106.049015

Nakamura, M., and Grebe, M. (2018). Outer, inner and planar polarity in the Arabidopsis root. Curr. Opin. Plant Biol. 41, 46-53. doi: 10.1016/j.pbi.2017.0 8.002

Naseer, S., Lee, Y., Lapierre, C., Franke, R., Nawrath, C., and Geldner, N. (2012). Casparian strip diffusion barrier in Arabidopsis is made of a lignin polymer without suberin. PNAS 109, 10101-10106. doi: 10.1073/pnas.1205726109

Nazoa, P., Vidmar, J. J., Tranbarger, T. J., Mouline, K., Damiani, I., Tillard, P., et al. (2003). Regulation of the nitrate transporter gene AtNRT2.1 in Arabidopsis thaliana: responses to nitrate, amino acids and developmental stage. Plan. Mol. Biol. 52, 689-703.

Neuhäuser, B., Dynowski, M., Mayer, M., and Ludewig, U. (2007). Regulation of $\mathrm{NH} 4+$ transport by essential cross talk between AMT monomers through the carboxyl tails. Plant Physiol. 143, 1651-1659. doi: 10.1104/pp.106.094243

Ogura, T., Kobayashi, N. I., Suzuki, H., Iwata, R. I., Nakanishi, T. M., and Tanoi, K. (2018). Magnesium uptake characteristics in Arabidopsis revealed by $28 \mathrm{Mg}$ tracer studies. Planta 248, 745-750. doi: 10.1007/s00425-018-2936-4

Pauluzzi, G., Divol, F., Puig, J., Guiderdoni, E., Dievart, A., and Périn, C. (2012). Surfing along the root ground tissue gene network. Dev. Biol. 365, 14-22. doi: 10.1016/j.ydbio.2012.02.007

Pfister, A., Barberon, M., Alassimone, J., Kalmbach, L., Lee, Y., Vermeer, J. E., et al. (2014). A receptor-like kinase mutant with absent endodermal diffusion barrier displays selective nutrient homeostasis defects. eLife 3:e03115. doi: 10 . 7554/eLife.03115

Rae, A. L., and Smith, F. W. (2002). Localisation of expression of a high-affinity sulfate transporter in barley roots. Planta 215, 565-568. doi: 10.1007/s00425002-0777-6

Ranathunge, K., Bi, Y.-M., and Rothstein, S. J. (2016). Ammonium-induced architectural and anatomical changes with altered suberin and lignin levels significantly change water and solute permeabilities of rice (Oryza sativa L.) roots. Planta 243, 231-249. doi: 10.1007/s00425-015-2406-1

Reintanz, B., Szyroki, A., Ivashikina, N., Ache, P., Godde, M., Becker, D., et al. (2002). AtKC1, a silent arabidopsis potassium channel $\alpha$-subunit modulates root hair K+ influx. PNAS 99, 4079-4084. doi: 10.1073/pnas.052677799

Robbins, N. E., Trontin, C., Duan, L., and Dinneny, J. R. (2014). Beyond the barrier: communication in the root through the endodermis. Plant Physiol. 166, 551-559. doi: 10.1104/pp.114.244871

Roppolo, D., De Rybel, B., Dénervaud Tendon, V., Pfister, A., Alassimone, J., Vermeer, J. E., et al. (2011). A novel protein family mediates Casparian strip formation in the endodermis. Nature 473, 380-383. doi: 10.1038/nature10070

Ryu, K. H., Huang, L., Kang, H. M., and Schiefelbein, J. (2019). Single-cell RNA sequencing resolves molecular relationships among individual plant cells. Plant Physiol. 179, 1444-1456. doi: 10.1104/pp.18.01482

Sakurai, J., Ahamed, A., Murai, M., Maeshima, M., and Uemura, M. (2008). Tissue and cell-specific localization of rice aquaporins and their water transport activities. Plant Cell Physiol. 49, 30-39. doi: 10.1093/pcp/pcm 162

Sasaki, A., Yamaji, N., and Ma, J. F. (2016). Transporters involved in mineral nutrient uptake in rice. J. Exp. Bot. 67, 3645-3653. doi: 10.1093/jxb/erw060

Sasaki, A., Yamaji, N., Yokosho, K., and Ma, J. F. (2012). Nramp5 is a major transporter responsible for manganese and cadmium uptake in rice. Plant Cell 24, 2155-2167. doi: 10.1105/tpc.112.096925

Schaaf, G., Schikora, A., Häberle, J., Vert, G. A., Ludewig, U., Briat, J. F., et al. (2005). A putative function for the Arabidopsis Fe-phytosiderophore transporter homolog AtYSL2 in Fe and Zn homeostasis. Plant Cell Physiol. 46, 762-774. doi: 10.1093/pcp/pci081

Shao, J. F., Yamaji, N., Shen, R. F., and Ma, J. F. (2017). The key to Mn homeostasis in plants: regulation of Mn transporters. Trends Plant Sci. 22, 215-224. doi: 10.1016/j.tplants.2016.12.005

Shi, H., Quintero, F. J., Pardo, J. M., and Zhu, J. K. (2002). The putative plasma membrane $\mathrm{Na}+/ \mathrm{H}+$ antiporter SOS1 controls long-distance $\mathrm{Na}+$ transport in plants. Plant Cell 14, 465-477. doi: 10.1105/tpc.010371

Stahl, Y., and Simon, R. (2013). Gated communities: apoplastic and symplastic signals converge at plasmodesmata to control cell fates. J. Exp. Bot. 64, 52375241. doi: 10.1093/jxb/ert245

Steudle, E. (2000). Water uptake by plant roots: an integration of views. Plant Soil $226,45-56$. 
Steudle, E., and Peterson, C. (1998). How does water get through roots? J. Exp. Bot. 322, 775-788. doi: 10.1093/jexbot/49.322.775

Takano, J., Miwa, K., and Fujiwara, T. (2008). Boron transport mechanisms: collaboration of channels and transporters. Trends Plant Sci. 13, 451-457. doi: 10.1016/jtplants.2008.05.007

Takano, J., Miwa, K., Yuan, L., von Wirén, N., and Fujiwara, T. (2005). Endocytosis and degradation of BOR1, a boron transporter of Arabidopsis thaliana, regulated by boron availability. PNAS 102, 12276-12281. doi: 10.1073/pnas. 0502060102

Takano, J., Tanaka, M., Toyoda, A., Miwa, K., Kasai, K., Fuji, K., et al. (2010). Polar localization and degradation of Arabidopsis boron transporters through distinct trafficking pathways. PNAS 107, 5220-5225. doi: 10.1073/pnas.09107 44107

Ueno, D., Sasaki, A., Yamaji, N., Miyaji, T., Fuji, Y., Takemoto, Y., et al. (2015). A polarly localized transporter for efficient manganese uptake in rice. Nat. Plants 1:15170. doi: 10.1038/nplants.2015.170

Véry, A., Nieves-Cordones, M., Daly, M., Khan, I., Fizames, C., and Sentenac, H. (2014). Molecular biology of $\mathrm{K}+$ transport across the plant cell membrane: what do we learn from comparison between plant species? J. Plant Physiol. 171, 748-769. doi: 10.1016/j.jplph.2014.01.011

Walker, L., Boddington, C., Jenkins, D., Wang, Y., Grønlund, J. T., Hulsmans, J., et al. (2017). Changes in gene expression in space and time orchestrate environmentally mediated shaping of root architecture. Plant Cell 29, 2393 2412. doi: $10.1105 /$ tpc. 16.00961

Wang, S., Yoshinari, A., Shimada, T., Hara-Nishimura, I., Mitani-Ueno, N., Ma, J. F., et al. (2017). Polar localization of the NIP5;1 boric acid channel is maintained by endocytosis and facilitates boron transport in Arabidopsis roots. Plant Cell 29, 824-842. doi: 10.1105/tpc.16.00825

Yuan, L., Loque, D., Kojima, S., Rauch, S., Ishiyama, K., Inoue, E., et al. (2007). The organization of high-affinity ammonium uptake in Arabidopsis roots depends on the spatial arrangement and biochemical properties of AMT1-type transporters. Plant Cell 19, 2636-2652. doi: 10.1105/tpc.107. 052134

Conflict of Interest Statement: The authors declare that the research was conducted in the absence of any commercial or financial relationships that could be construed as a potential conflict of interest.

Copyright (C) 2019 Bao, Bai, Cui and Gong. This is an open-access article distributed under the terms of the Creative Commons Attribution License (CC BY). The use, distribution or reproduction in other forums is permitted, provided the original author(s) and the copyright owner(s) are credited and that the original publication in this journal is cited, in accordance with accepted academic practice. No use, distribution or reproduction is permitted which does not comply with these terms. 